\title{
Heidegger: origem e finitude do tempo
}

\author{
Róbson Ramos dos Reis \\ Universidade Federal de Santa Maria
}

\begin{abstract}
resumo Neste artigo apresento os traços gerais da doutrina heideggeriana da temporalidade, emSer e Tempo. Além de destacar os aspectos ontológicos que caracterizam tal abordagem, acentuo uma característica central da assim chamada cronologia fenomenológica, a saber: a identificação de modos do tempo e o a determinação de uma relação de dependência explicativa entre eles. A finitude da temporalidade e a gênese dos modos do tempo a partir da temporalidade originária do Dasein são analisadas com maior ênfase. $O$ artigo é encerrado com uma breve consideração de quatro tópicos que certamente devem ser abordados com maior detalhe em uma posterior análise da cronologia fenomenológica de Heidegger.
\end{abstract}

palavras-chave Fenomenologia - Heidegger - Temporalidade

O recurso a tais provas documentais deve evitar cair em uma desenfreada mística das palavras; entretanto, em última instância forma parte do ofício da filosofia preservar a força mais elementar das palavras nas quais o ser-aí se expressa, impedindo o seu nivelamento pelo entendimento comum a um plano de incompreensibilidade, que por sua vez opera como fonte de pseudo-problemas.

(HEIDEGGER, 1986, p. 220)

Nesta passagem de Ser e Tempo Heidegger aponta para a historicidade própria aos conceitos e à terminologia filosófica. Como a própria existência humana, a história dos conceitos filosóficos é caracterizada por um movimento de perda e ruptura, resultando como parte essencial da atividade construtiva da investigação filosófica um esforço de preservação, 


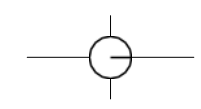

\section{0}

mais exatamente de preservação da força elementar das palavras. A passagem acima citada é antecedida por considerações sobre o significado de termos filosóficos da tradição grega, e por isso a declaração sobre evitar a "mística desenfreada das palavras". No entanto, aparentemente há um componente místico em uma concepção que atribui uma força elementar às palavras pura e simplesmente.

Desde o início de sua carreira filosófica Heidegger esteve envolvido com o problema metafilosófico sobre a natureza dos conceitos filosóficos e sobre o significado das expressões lingüísticas que expressam tais conceitos (CROWELL, 2001, p. 77). O resultado destas preocupações foi elaborado na doutrina do significado indicativo-formal dos conceitos filosóficos ${ }^{2}$, segundo a qual o significado de conceitos filosóficos seria dependente de uma recepção que desenvolva as direções significativas apenas indicadas em tais conceitos. Termos filosóficos, que são palavras pelas quais o ser-aí se expressa, reúnem indicações significativas impotentes para prevenir o nivelamento e a perda de possibilidades semânticas que acontece na história de sua transmissão. Ora, é somente com uma recepção aplicativa que se pode preservar a força presente nos termos filosóficos.

Não obstante esta teoria dos conceitos filosóficos, para muitos Heidegger fracassou na tarefa de preservação da força das palavras filosóficas, em particular daquelas que são centrais para o seu programa filosófico: "ser" e "tempo". Desde a publicação de Ser e Tempo apareceu uma recepção crítica que aponta para a obscuridade no uso do termo ser, isto é, para a mais completa falta de preservação dos significados canônicos do termo ser e das correspondentes tentativas de sua elucidação na história da filosofia. Do mesmo modo, a simples leitura dos parágrafos de Ser e Tempo relativos à temporalidade despertam no leitor a imediata impressão de uma doutrina muito exótica do tempo e a suspeita de que, na suposição de que se tenha presente uma fenômeno digno de consideração, pouco ou nada ele tem a ver com uma noção comum e mesmo filosófica de tempo. É deste contexto que surge a motivação da presente contribuição, cujo objetivo é simplesmente o de destacar alguns traços gerais do tratamento do fenômeno do tempo empreendido por Heidegger ao longo da sua obra até o final dos trinta. A minha hipótese é que sobretudo em relação ao conceito de tempo é preciso ter presente a semântica dos conceitos filosóficos como indicações formais ${ }^{3}$. Consequentemente, é preciso identificar as direções e possibilidades semânticas formalmente indicadas no conceito de temporalidade, reconhecendo ad initio que apenas isto é oferecido em Sere Tempo, desenvolvendo-as e levando-as aos 
seus limites. Somente assim, se estará em condições de avaliar o ganho ou a perda em verdade que se pode esperar de uma tal interpretação fenomenológica do tempo.

O programa fenomenológico-hermenêutico esboçado por Heidegger assume o compromisso com algumas teses fundamentais. Nos seus pontos mais estruturais, este programa filosófico apresenta um vínculo medular com o problema do tempo, na tese de que o sentido do ser em geral é o tempo. Neste plano ontológico ainda há um determinação adicional, que relaciona a identidade entre ser e nada com o problema do tempo. $\mathrm{Na}$ medida em que fenomenologicamente elucidada, a co-pertinência de ser e nada exigirá que a negatividade em geral, bem como a própria negação enquanto função formal, sejam interpretadas a partir da essência do tempo. A estas duas teses liga-se de forma elementar um terceiro e conhecido compromisso filosófico, que afirma que o sentido do ser do ser-humano, caso esteja apresentado conceitualmente por uma análise apropriada, é o tempo. O tempo é o plano conceitual último a partir do qual podem ser interpretados as estruturas formais que compõem o ser do existente humano, o que implica não apenas a demonstração da historicidade da existência, mas sobretudo a compreensão da unidade e totalidade que constituem o seu ser. Por fim, o método e os conceitos requeridos para elaborar e justificar tais teses também são internamente vinculados ao tempo. Seja no fundamento da historicidade dos conceitos filosóficos, seja no questionamento da distinção entre filosofia sistemática e filosofia histórica, a qualificação hermenêutica da fenomenologia é resultante da ligação interna entre tempo e filosofia.A apropriação interpretativa da história da filosofia, a chamada destruição da história da ontologia que deve consolidar a interpretação de ser pelo tempo, é realizada exatamente pelo eixo do conceito de tempo.

$\mathrm{Na}$ presente contribuição examinarei estes quatro elementos, com o intuito de apresentar em destaque alguns traços gerais da abordagem heideggeriana do tempo. O centro de atenção da minha exposição estará posto em dois eixos: a finitude e a gênese ontológica do tempo. Para não exceder os limites expositivos, não examinarei os elementos históricodestrutivos que compõem tal tratamento da temporalidade, pois isto envolveria o exame da apropriação feita por Heidegger de aspectos centrais da filosofia de Husserl, Bergson, Hegel, Kant, Agostinho, Aristóteles, assim como da tradição neoplatônica e da mística medieval. Como conclusão apresentarei três problematizações críticas apresentadas ao programa heideggeriano de uma abordagem filosófica do tempo. 
102

\section{Cronologia fenomenológica}

No curso do inverno dos anos 1925-26 (Lógica, a pergunta pela verdade), a abordagem filosófica da estrutura temporal dos fenômenos é denominada cronologia fenomenológica ${ }^{4}$. Inicialmente, ele esclarece que dizer de um fenômeno que ele é temporal não significa dizer que ele é um processo ou um movimento, e menos ainda que ele se realiza no tempo. Nos termos de Heidegger:

A tarefa da investigação da temporalidade dos fenômenos é tal que se refere a estas próprias determinações temporais e, portanto, caso ela seja filosófica, refere-se ao tempo enquanto tal. Chamamos de cronologia, de fato cronologia fenomenológica, esta consideração filosófica fundamental que tem como tema o tempo. ... Com o adjetivo cronologia "fenomenológica" deve ser indicado que este logos do tempo, esta investigação do tempo, está orientada filosoficamente, e inicialmente nada tem a ver com contagem do tempo e doutrina da contagem do tempo. A tarefa de uma cronologia fenomenológica é a investigação da determinidade temporal dos fenômenos - quer dizer, de sua temporalidade - e com isso é a investigação do próprio tempo. (HEIDEGGER, 1976b, p. 199-200)

Esta passagem é especialmente clara ao destacar que uma investigação filosófica da estrutura temporal dos fenômenos deve investigar também o próprio tempo. A passagem também sugere que o que seja o tempo enquanto tal não é acessível pura e simplesmente, mas a estrutura temporal dos fenômenos é que nos conduz a uma determinação do tempo. E Heidegger considera que a própria idéia de uma tal cronologia não está ainda propriamente descoberta, implicando que o seu domínio de investigação encontre-se ainda não elaborado 5 .

De imediato apresenta-se a pergunta pelo campo dos fenômenos que deverão ser investigados temporalmente, ou melhor, quais são os fenômenos para uma investigação especificamente filosófica. A resposta é muito conhecida, e está na base da explícita identificação entre filosofia, fenomenologia e ontologia. No $\S 7$ de Sere Tempo, Heidegger discrimina duas noções desformalizadas de fenômeno: os fenômenos em sentido comum e os fenômenos em sentido propriamente fenomenológico. Estes últimos referem-se àquilo que condiciona e torna possível o comportamento intencional, para com algo: é o que opera como seu sentido e fundamento, diz Heidegger (HEIDEGGER, 1986, p. 35). O termo tradi- 
cional para designar este plano de fenômenos é ser, e, assim sendo, o domínio de uma cronologia fenomenológica volta-se para a ontologia, mais especificamente, para a estrutura temporal de ser. Neste contexto, duas são as promissórias definitórias do programa de Sere Tempo: o tempo é o sentido do ser em geral, e o tempo é o sentido do ser do ser-humano.

A relação entre ser e tempo estabelecida a partir do conceito de sentido manifesta a determinação hermenêutica da ontologia fenomenológica. De um lado temos uma análise da estrutura da intencionalidade, nos termos de uma pressuposição inerente a todo comportamento intencional. Em síntese esta análise discrimina um terceiro momento estrutural em todo comportamento para com algo, ao lado de noema e noesis, a saber, um acesso ao padrão de identificação ontológico determinante do correlato objetual do comportamento. Esta posição foi enunciada na forma de uma relação de pressuposição, pretendendo que todo comportamento para com algo enquanto algo determinado pressupõe um acesso ou desvelamento do ser daquilo que está sendo visado como algo. Heidegger também formulou esta tese a partir do conceito de transcendência, dizendo que o comportamento para com entes seria um tipo de transcendência ôntica, possibilitada por uma abertura para o ser do correlato objetual em questão, isto é, uma transcendência primitiva.

De outro lado, o conceito de sentido é introduzido para destacar a determinação hermenêutica de tal relação de pressuposição. O desvelamento do padrão ontológico suposto no comportamento para com entes é de natureza compreensiva, isto é, a pressuposição de ser no comportamento intencional é determinada como uma compreensão de ser. A partir da conhecida análise dos conceitos de compreensão e sentido apresentada em Sere Tempo (§ 31), a compreensão de ser possui a estrutura de uma projeção, de um projeto. Conseqüentemente, o sentido de ser não se refere a um plano teleológico ou valorativo, mas sim ao componente ou perspectiva a partir do qual algo é compreendido ou projetado. Neste caso, 'algo' não é um objeto ou ente, mas um padrão de identificação e individuação que possibilita o manifestar-se ou aparecer de entes. Sentido de ser refere-se ao plano da projeção dos diferentes padrões ontológicos, e o esforço de conceitualização deste plano situa-se na procura de uma resposta que explicite o elemento formal que estrutura toda projeção ou compreensão de ser. Em Ser e Tempo, Heidegger reconhece cinco categorias ou sentidos em que ser está compreendido: consistência (Bestand), subsistência (Vorhandenheit), disponibilidade (Zuhandenheit), existência (Existenz) e vida (Leben). 


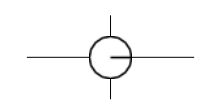

\section{4}

Ora, a construção fenomenológica afirma que, seja qual for o padrão ontológico que estiver desvelado em um comportamento para com entes, a sua projeção acontece em um horizonte temporal. Ou seja, a perspectiva formal a partir da qual ser é compreendido e projetado é o tempo. Esta construção pretende ser também uma explicitação de um critério de regionalização ontológica que, segundo Heidegger, tem operado de modo não temático ao longo da história da ontologia. De outro lado, uma tal construção precisa ser elaborada e concretamente exposta. Para que isso seja o caso, um empreendimento fundamental deve ser levado a cabo, a saber: mostrar que o tempo é o sentido do ser do serhumano, isto é, que o modo de ser próprio do ser-humano é compreensível a partir do tempo.A arquitetura desta construção é bem conhecida, e apenas recordo os traços elementares do seu esboço. Dado que a compreensão de ser pressuposta em todo comportamento intencional é própria de um ente particular (o ser-humano, que por esta razão é qualificado como ser-aí, Dasein), a tematização de tal compreensão requer a explicitação conceitual do ser do ser-humano. Esta explicitação apresenta certas estruturas formais, que não são propriamente categorias, mas formas em que se estruturam as possibilidades existenciais. Estes elementos formais não perfazem um agregado ou totalidade abstrata, mas sim uma totalidade concreta ${ }^{6}$. O conceito que possibilita mostrar como um todo unificado este conjunto de momentos estruturais é o que será chamado de ser do Dasein,o qual, segundo Heidegger, está expresso pela noção de cuidado (Sorge).Assim sendo, surge o problema de mostrar que o tempo é precisamente a perspectiva que explicita a projeção do cuidado, ou seja, que permite a compreensão da unificação de tais momentos em um todo concreto.

Assim, fica estabelecido um vínculo fundacional entre as duas teses, pois é em razão do tempo ser o sentido do ser do ser-humano, condicionando formalmente todas as suas estruturas (entre as quais está a compreensão), que o sentido do ser em geral estará identificado no tempo. Heidegger distingue estas duas funções da temporalidade, usando o termo latino Temporalität para designar o sentido do ser em geral, e o termo germânico Zeitlichkeit, para designar o sentido do ser do Dasein em particular. Em ambas as direções, no entanto, a ontologia fenomenológica implica uma cronologia fenomenológica.

Antes de examinar os elementos construtivos de tal cronologia, vale ressaltar as implicações da qualificação hermenêutica desta ontologia fenomenológica. Inicialmente, há o aspecto central do conceito de 


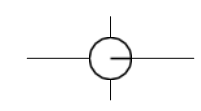

compreensão, e da recepção da tradição hermenêutica operada por Heidegger, que permitiria sair da dicotomia intuição e pensamento. De outro lado, a compreensão elabora-se em interpretação e expressão lingüística, de tal forma que as projeções de ser operadas pelo serhumano encontram-se sempre em tradições ou compreensões elaboradas. Temos, portanto, um componente de historicidade trazido para o interior da ontologia da existência e do próprio sentido do ser em geral. Por fim, a relatividade de todo ser à compreensão de ser e à temporalidade aparentemente introduzem um componente idealista irrecusável na ontologia hermenêutica. Não obstante, deve ser lembrado que o aparente antropologismo da relativização de ser e verdade ao Dasein foi expressamente recusado por Heidegger, ao afirmar que o conceito de Dasein implicava um descentramento da subjetividade e de forma alguma comprometia-se com um decrescimento da possível validade universal que os comportamentos cognitivos promovem em relação a domínios de entes.

\section{Os modosdo tempo}

Ao apresentar a estrutura temporal de um fenômeno (ser e ser do Dasein), a cronologia fenomenológica deve determinar o próprio tempo enquanto tal. Mas o que é o tempo, segundo tal cronologia? Uma consideração formal, coerente com a hipótese de que o sentido do ser é o tempo, localizará o próprio tempo no plano ontológico da assim chamada diferença ontológica (a diferença entre ser e ente) ${ }^{7}$. Ou seja, aquilo que é ser, o padrão de individuação que permite o aparecer e o acesso aos entes, não é um ente ou objeto. Desta forma, o que pertence ao plano do sentido do ser, isto é, ao plano da perspectiva de projeção e compreensão de ser, tampouco é um ente ou mesmo uma relação entre entes. Este é o significado da afirmação segundo a qual o tempo não é, mas sim se temporaliza ou produz a si mesmo.

Tempo não pode em geral ser subsistente, ele não possui nenhum tipo de ser - ao contrário ele é a condição de possibilidade para que se dê algo assim como ser (não ente). Tempo não possui o tipo de ser de alguma outra coisa, mas ao contrário se temporaliza (zeitigt). $\mathrm{O}$ temporalizar (Zeitigen) constitui sua temporalidade (Zeitlichkeit). (HEIDEGGER, 1976b, p. 410) 


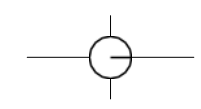

\section{6}

Além desta qualificação formal, a doutrina do tempo sugerida por Heidegger não vai lhe atribuir nenhuma categoria ontológica propriamente dita, mas vincula o tempo à modalidade. Ou seja, não temos um plano temporal homogêneo e unitário, mas sim modos do tempo. Que o tempo se temporaliza significa, então, que o tempo produz a si mesmo segundo diferentes modos, modos que deverão ser explicitados e conceitualizados ao se apresentar a estrutura temporal de algum fenômeno. Já em 1924, na conferência na Faculdade de Teologia de Marburg, Heidegger apontava nesta direção ao afirmar que:

Para corresponder ao caráter de ser do que aqui é tema, devemos falar temporalmente sobre o tempo. Queremos retomar temporalmente a questão sobre o tempo. O tempo é o como (das Wie). Se perguntamos pelo que é o tempo, então não devemos agarrar-nos precipitadamente a uma resposta - isto ou aquilo é o tempo - que sempre designa um o que (ein Was). (HEIDEGGER, 1997, p. 39)

Antes de considerar os diferentes modos do tempo reconhecidos por Heidegger no período de Ser e Tempo,é importante ressaltar o significado interpretativo da temporalidade, que está expresso no vínculo entre o conceito de tempo e o conceito de sentido (Sinn).Apresentar a estrutura temporal de um fenômeno é apresentar o seu sentido temporal. É conhecida a ampliação do conceito de sentido operada por Heidegger em relação ao conceito lógico de sentido, que era entendido na tradição da Lógica daValidade como o conteúdo judicativo capaz de ser o portador de um valor de verdade. Para além disso, sentido designa uma perspectiva estruturada do projeto, a partir do qual algo é compreensível como algo (HEIDEGGER, 1986, p. 151). Esta formulação é retomada quando Heidegger introduz a noção de temporalidade, adicionando, porém, que sentido é a perspectiva de uma projeção primária, pela qual algo pode ser apanhado na possibilidade a partir da qual é. A noção de possibilidade liga-se, portanto, ao conceito de sentido (HEIDEGGER, 1986, p. 324).

Assim sendo, o conceito de tempo tem uma função expressamente interpretativa, isto é, a partir dele é possível tornar explícita a projeção ontológica de um dado fenômeno. Destacar a sua estrutura temporal é explicitar a perspectiva a partir da qual foi projetado, o que significa interpretação, elaboração de uma compreensão. Como já foi visto, Heidegger pretende que o tempo é o sentido do ser do Dasein e o sentido do ser em geral. O tempo funciona, portanto, como a perspectiva de projeção que 
possibilita tanto compreender o existente humano em seu ser, assim como compreender qualquer modo de ser possível.

$\mathrm{Na}$ construção da ontologia fundamental, como é bem conhecido, o tempo é inicialmente apresentado como o sentido do ser do Dasein,ou então, como o sentido do cuidado (Sorge). Neste tópico é relevante considerar que o conceito de cuidado proporciona a resposta ao problema da totalidade do todo de estruturas da existência. A exigência que o conceito de cuidado satisfaz é de apresentar as estruturas existenciais em uma unidade, destacando sua co-originariedade e suas possibilidades de modificação existencial (HEIDEGGER, 1986, p. 181). O conceito de cuidado é uma projeção, portanto, que permite visualizar as estruturas formais da existência como momentos unitários e originários de uma totalidade. Apresentar a estrutura temporal do ser do Dasein deve significar um ganho interpretativo a mais, para além daquele proporcionado pelo próprio conceito de cuidado. Em verdade, este ganho consiste em tornar explicita a perspectiva já presente no projeto do ser do Dasein, mais especificamente a pergunta pelo sentido do cuidado afeta $\mathrm{o}$ componente unitário da totalidade de estruturas da existência. $\mathrm{O}$ sentido do cuidado responde, em suma, por aquilo que perfaz a unidade da existência, aquilo que possibilita o todo existencial como uma totalidade concreta. Consequentemente, ao interpretar o ser do ser-humano a partir da temporalidade, o que se está proporcionando é a explicitação de uma estrutura já presente na projeção compreensiva da noção de cuidado $^{8}$.

Voltando ao conceito de tempo propriamente dito, a interpretação temporal do ser do ser-humano não pode partir irrefletidamente de uma noção previamente estabelecida de tempo.Apresentar a estrutura temporal do cuidado deve lançar luz no próprio tempo. Visto reconstrutivamente, a temporalidade é fundamentalmente caracterizada por modos 9 . Especialmente no caso do ser-humano, pretender que o seu ser possua uma estrutura temporal não é afirmar que o ser-humano ocorre no tempo, como um possível elemento de uma série temporal (seja qual for). Tampouco significa afirmar que a existência humana é um fluxo temporal.A estrutura temporal do ser-humano, a partir da qual compreende-se a projeção do seu ser como cuidado, representa a unidade de modos temporais. Estes modos do tempo são três: temporalidade originária, tempo do mundo e o tempo comum (apanhado no conceito vulgar de tempo). $\mathrm{O}$ tempo como sentido do ser do Dasein é a temporalidade originária.

Como também é conhecido, não apenas são distinguidos diferentes conceitos de tempo, referentes aos seus diferentes modos, mas é estabele- 


\section{8}

cida uma tese genealógica, segundo a qual os dois modos restantes do tempo originam-se da temporalidade existencial e originária. O tempo em sentido usual não é avaliado como uma noção problemática, mas considerado como explicável a partir de noções mais fundamentais e originárias do tempo. Haveria um erro, isto sim, caso um destes modos em geral a noção comum, serial e não qualitativa de tempo - seja tomada como a única ou mais fundamental expressão do fenômeno do tempo (HEIDEGGER, 1986, p. 326, HEIDEGGER, 1976b, p. 238, 254-255).

Assim sendo, não apenas o tempo gera modos de si mesmo, com características próprias e modificáveis, como estes modos são produzidos a partir de modificações e complexificações nas estruturas dos modos temporais mais básicos. Ao final, abordagem genealógica, operando com uma noção não empírica ou histórica de gênese, apresenta uma imagem do tempo como a diversidade de diferentes modos, originando-se a partir de alterações nas estruturas dos modos mais elementares. A cronologia fenomenológica compromete-se com uma abordagem genealógica, que pretende exibir as modificações na produção dos modos do tempo a partir de um modo mais originário, isto é, como a apresentação da origem do tempo.

\section{A temporalidade originária}

Em Ser eTempo, Heidegger apresenta três modos do tempo e suas relações de modificação estrutural: a temporalidade originária, o tempo do mundo e o tempo em sentido comum. No que segue apresentarei brevemente as características da temporalidade originária, sem empreender uma análise detalhada de suas estruturas. Também não examinarei a aplicação específica do modelo interpretativo da temporalidade em cada um dos casos das modificações das estruturas existenciais, mesmo que esta seja uma etapa central na própria formulação do modelo da temporalidade.

Negativamente considerada, a temporalidade originária não pode ser caracterizada nem como um tempo interno, nem como um tempo subjetivo, e sobretudo não pode ser caracterizada como uma série ou seqüência. Ela não é relativa à sensibilidade ${ }^{10}$, conseqüentemente, não é a forma pela qual a mente ou a consciência representa a si mesma. Neste sentido, a temporalidade originária não é uma forma condicionante da percepção em geral, e da percepção de si mesmo em particular, e tampouco é uma forma de representação ou de organização de representações ${ }^{11}$. Não tere- 
mos uma adequada descrição da temporalidade originária a partir da diferença descrita pelos conceitos de interno / externo. O ser humano como Dasein e cuidado não é uma interioridade, distinto de todos os demais objetos que lhe seriam exteriores. $\mathrm{O}$ conceito de cuidado pretende marcar a exterioridade do Dasein, pois as possibilidades pelas quais se identifica estão estabilizadas de forma impessoal e a partir das demandas originadas da relação primitiva com outras pessoas e outros entes ${ }^{12}$. Neste sentido, a temporalidade originária não é um tempo interior.

Também não é adequado caracterizar formalmente a temporalidade originária pelo par conceitual subjetivo-objetivo, pretendendo que ela seja um caso do tempo subjetivo. É claro que, em uma acepção muito geral da expressão "sujeito" deve-se alinhar a temporalidade originária ao tipo fundamental do tempo chamado de tempo subjetivo13.A temporalidade originária é vista como o modelo interpretativo capaz de explicitar a projeção ontológica que é própria de todos os comportamentos do Dasein existente, e neste sentido seria possível descrevê-la como um caso de tempo subjetivo. Não obstante, em uma acepção mais específica os compromissos da distinção sujeito-objeto trariam consigo as pressuposições que estão suspensas ao início da ontologia fundamental. Heidegger é explícito a este respeito: "'O tempo' não é subsistente nem no 'sujeito' nem no 'objeto', não está 'dentro' nem 'fora', mas 'é' 'anterior' a toda subjetividade e objetividade, porque ele representa a própria condição de possibilidade para este 'anterior'" (HEIDEGGER, 1986, p. 419).

No entanto, o aspecto mais controvertido da noção de temporalidade originária é que ela não pode ser descrita em termos seriais ou seqüenciais. A temporalidade originária não forma uma série, mas sim uma multiplicidade unificada de momentos estruturais que Heidegger denomina ekstases. Estes momentos são identificados por termos temporais usuais (presente, passado e futuro), apesar da advertência em relação ao significado próprio que eles adquirem na temporalidade originária. Não obstante, a temporalidade originária não é uma série de elementos seqüencialmente distribuídos. Deste modo, não é adequado buscar uma aproximação da noção de temporalidade originária com a diferença conhecida entre a série A e a série B, com a qual Mactaggart ofereceu a caracterização do tempo no seu clássico trabalho de 1905. Certamente que a temporalidade originária não se refere a uma série cujos elementos estariam relacionados pelas relações de "antes de ..." e "depois de ...", mas tampouco ela é a série formada por elementos caracterizados como "presente", "passado" e "futuro". O traço único e polêmico do conceito 


\section{0}

de temporalidade originária é que ele não contempla serialidade ou seqüencialidade.

Em termos positivos, a temporalidade originária é caracterizada como ekstática, horizontal e finita. Além disso, ela é temporalização, ela se temporaliza unificando os momentos ekstáticos. A unidade móvel em que os três ekstases estão presentes é, por sua vez, variável segundo o ponto de partida da temporalização, gerando as modificações pelas quais são interpretadas as estruturas existenciais. Não havendo serialidade na temporalidade originária, os seus ekstases são ditos co-originários, apesar do primado do futuro na temporalização da temporalidade. E este é um outro traço característico da temporalidade originária: a temporalidade temporaliza-se originariamente a partir do futuro.

O futuro originário não se refere a um momento ainda não presente, posto em uma relação de posteridade com o momento atual, e que pode ser tomado como o ponto de aproximação na seqüência da série temporal. Futuro quer dizer aqui o "chegar-a-si-mesmo", discriminando pelo menos dois aspectos: a formação de individualidade na ontologia existencial e o saber de si como tal individualidade. Que o ser-humano é porvindouro quer dizer que sua individualidade é estabelecida por um modo de estar em possibilidades, estabelecimento que é feito não reflexivamente, mas por um acontecimento que sobrevém. Cada existente singular não é portador de uma individualidade, mas ela chega a cada um como que por uma doação, por assim dizer. Em tal chegar ao si mesmo próprio cada indivíduo humano compreende-se como tal: o futuro significa aqui a impossibilidade de não compreender-se como o indivíduo que se é14. O futuro temporaliza-se, produzindo os ekstases do passado e do presente, formando uma unidade.

Ao traço ekstático da temporalidade originária liga-se o seu componente horizontal. Cada ekstase possui um esquema, que seria a demarcação formal, ou horizonte, do seu respectivo deslocamento. A unidade dos ekstases da temporalidade originária é relativa a uma unidade dos esquemas horizontais. Com este modelo ekstático-horizontal é possível empreender a demonstração da estrutura temporal do cuidado, e da tese do tempo como sentido do ser do Dasein.A unidade dos horizontes, por sua vez, constituiria a delimitação formal da compreensão de ser em geral e da transcendência do ser humano para o mundo.

Os ekstases da temporalidade perfazem uma unidade, na qual sempre estão presentes em conjunto, e determinando-se a partir de um ekstase primário.A modificação fundamental da temporalidade originária acom- 
panha a diferença modal primitiva da existência humana, a saber: autenticidade e inautenticidade. Deste modo, há uma temporalidade originária autêntica e inautêntica, com uma unidade de futuro, passado e presente autênticos e inautênticos ${ }^{15}$.

O primado do futuro é um aspecto fundamental na produção ou temporalização na temporalidade originária, e é consistente com a modalidade existencial do Dasein. O poder-ser, a possibilidade, é a determinação última na ontologia da existência, e explicita a determinidade do ser-humano, que não é caracterizado por ser portador de propriedades, mas por lançar-se projetivamente em possibilidades. Em termos temporais, a temporalização acontece a partir do ekstase do futuro, e Heidegger ressalta expressamente que o fenômeno primário da temporalidade autêntica e originária é o futuro' ${ }^{16}$. Que Heidegger tenha destacado o futuro como o fenômeno primário da temporalidade originária, usando a expressão metodológica "fenômeno", é indicativo da direção que deve ser compreendida uma outra tese polêmica na doutrina do tempo: a finitude.

\section{A temporalidade finita}

A finitude é um dos componentes estruturais da temporalidade originária que mais diretamente contradiz as noções usuais do tempo, pois a estas ligam-se os aspectos de infinitude ou ilimitação na série temporal. À ausência de serialidade do tempo, Heidegger liga a finitude, novamente levantando a suspeita de um abuso lingüístico ao chamar de tempo um modelo interpretativo assim caracterizado. A dificuldade cresce quando consideramos que a elucidação positiva deste traço fenomenal da temporalidade originária é operada por recurso a outros conceitos centrais da ontologia fundamental, mas que também apresentam uma significação distante da usual. É o caso com os conceitos de finitude, limite e morte.

Inicialmente, é importante ressaltar que a finitude do tempo não significa que ele acabe ou não prossiga a partir de um determinado ponto da série. Como a temporalidade originária não constitui uma série ou seqüência, então a finitude não diz respeito a uma limitação em uma série ou em sua progressão.A finitude temporal é relativa às noções de limite e morte, mas estas noções deverão ser tomadas no marco da ontologia existencial. Assim, a finitude da existência não é o seu acabamento, encerramento ou completude. Em termos positivos, a compreensão da tese da 


\section{2}

finitude da temporalidade originária requer a adequada compreensão dos conceitos de futuro e de finitude existencial.Ainda deve ser acrescentada a qualificação fundamental para a compreensão da finitude temporal, que está no seu caráter fenomenal. A finitude da temporalidade é a maneira como o futuro torna-se fenômeno, ou então, o modo como acontece o chegar a si que individualiza.

O ponto de partida da análise é o conceito de morte (HEIDEGGER, 1986, p. 329). Em termos existenciais o ser-humano é mortal não porque sua vida tenha um fim, um limite, mas porque ele existe de modo finito. Esta é uma expressão técnica: a existência é determinada por possibilidades e a finitude é própria destas possibilidades como possibilidades existenciais.Assim, a finitude da existência, por seu turno, não denota um fim no qual ela termina, acaba, ou se completa. A finitude da existência vincula o conceito de possibilidade como o de negatividade (Nichtigkeit). Existir de modo finito é a determinação positiva das possibilidades humanas, e do modo como elas são projetadas e recebidas. Mais especificamente, a finitude é o elemento de negatividade que qualifica as possibilidades existenciais e o completo projetar-se nelas ${ }^{17}$.Apesar do aparente giro lingüístico, em toda possibilidade existencial há a possibilidade da pura e simples impossibilidade, mas não no sentido do fim das possibilidades pelo advento da morte. Diferentemente, como a possibilidade existencial não se efetiva, não se realiza ao ponto de constituir um feixe de propriedades, nela há sempre a impossibilidade. A morte tem este sentido, portanto, a saber: que as possibilidades em que cada existente se lança são inalcançáveis como uma propriedade que possa ser portada, que elas apenas são enquanto há projeto e lançamento.

Projetando-se em possibilidades que nunca são alcançáveis como propriedades de estado, cada existente encontra sua individuação, tornase um todo, isto é, pode estar em possibilidades de modo próprio e não impessoal. Cada existente humano torna-se indivíduo quando reconhece que sua identidade está dada por possibilidades, e não por propriedades, e que tais possibilidades nunca se tornam uma posse fundada, estável e justificada. Quando este reconhecimento acontece, então é possível apropriar-se das possibilidades de modo próprio, preservando-as ou projetando-se em outras: é possível desfragmentar-se, formando um todo não impessoal, mas singular, próprio. Dito sem o jargão, nos tornamos indivíduos quando reconhecemos a falta de fundamento de tudo o que somos. Quando nos defrontamos com a morte, chegamos a ser o indivíduo único que somos, em razão de sermos levados à decisão de continuar ou 
não nas possibilidades em que impessoalmente estamos nos lançando. Em conexão com o ser para a morte está, portanto, o futuro.

Já foi visto que o futuro originário quer dizer aqui o "chegar-a-simesmo", discriminando pelo menos dois aspectos: a formação de individualidade e o compreender a si mesmo como tal individualidade. A individualidade existencial não é uma posse. Cada indivíduo existencial não pode ser adequadamente descrito como um conjunto de propriedades que possuiria desde antes, agora, ou depois, mas a individuação é dada pelo modo de estar em possibilidades. Neste sentido, o futuro compromete-se com o porvir, é algo que chega, que sobrevém a cada existente no projetar-se em possibilidades determinadas. Como "porvindouros", os existentes humanos projetam-se em possibilidades e neste projetar a sua individuação se lhes alcança de forma irrecusável e inequívoca. Neste nível, futuro é chegar a si mesmo, é individualizar-se a partir do projeto em possibilidades.

Posto isto, qual é a relação entre o futuro e o ser para a morte, a finitude? Não é, certamente, uma relação de identidade, mas de dependência explanatória ou interpretativa. Ser para a morte, como foi visto, é projetar-se decididamente nas possibilidades impessoalmente recebidas, pelo reconhecimento da negatividade que lhes é inerente. Como entender esta projeção? Ela deve ser entendida como a formação da própria identidade, da própria individuação. O sentido do ser para a morte é o de chegar à individualidade própria, o que significa, na terminologia de Heidegger, a palavra futuro.Assim, o sentido do ser para a morte finito, a decisão antecipatória, é o futuro em sentido originário."O futuro autêntico, temporalizado primariamente pela temporalidade que constitui o sentido da decisão antecipatória, desvela-se assim, também ele,como finito" (HEIDEGGER, 1986,p. 329-330).

É nesta passagem que Heidegger qualifica o futuro originário como finito, afirmando que ao ser o futuro o sentido da decisão antecipatória isto o desvela como finito. A finitude do futuro mostra-se na sua relação hermenêutica para com o ser para a morte, há um componente fenomenológico, portanto, na finitude da temporalidade. Que o formar individualidade existencial seja a perspectiva a partir da qual deve-se compreender o que significa projetar-se decididamente em possibilidades negativas é o que possibilita visualizar a finitude do futuro, do chegar a si mesmo individualizador. A finitude do futuro desvela-se quando relacionamos a estrutura do ser para a morte e o ekstase do chegar a si mesmo individualizador. Tendo formulado a relação entre ser para a 


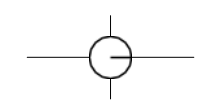

\section{4}

morte (antecipação decidida), futuro (chegar a si), e a finitude do futuro, Heidegger formula duas perguntas: a) o tempo não continua após a morte do indivíduo existente?; b) não há muita coisa que ainda está no futuro e que pode chegar desde aí? Sim, é a resposta para ambas. Com tal resposta não se objeta, porém, à finitude da temporalidade originária, precisamente porque não são perguntas que estejam lidando com o conceito existencial de morte e com o conceito não serial e não seqüencial de tempo (HEIDEGGER, 1986, p. 330), presentes no conceito de temporalidade originária. Mas o que entender por finitude neste caso?

Para iniciar uma resposta a esta pergunta, apresentarei a reconstrução da finitude da temporalidade através de um comentário textual imanente, sacrificando a elegância da exposição em nome de um esboço de clarificação ${ }^{18}$.

[1] A pergunta não é o que ainda pode acontecer em um tempo que ainda continua e qual deixar-chegar-a-si pode vir ao encontro "desde este tempo", mas como o próprio chegar-a-si como tal está originariamente determinado. [2] A sua finitude não quer dizer primariamente um acabar, mas sim é um caráter da própria temporalização. [3] O futuro originário e autêntico é o a-si (Auf-sich$z u$ ), a si, existindo como a possibilidade insuperável da negatividade. [4] O caráter ekstático do futuro originário reside precisamente em que ele fecha o poder-ser, quer dizer, que está já fechado e como tal possibilita a compreensão existenciária decidida da negatividade. [5] O chegar-a-si originário e autêntico é o sentido do existir na negatividade mais própria. [6] Com a tese da finitude originária da temporalidade não se torna questionável que "o tempo continua", mas ela meramente deve estabelecer o caráter fenomenal da temporalidade originária, que se mostra a si mesma no projetado do projeto existencial originário. (HEIDEGGER, 1986, p. 330)

[1] A finitude refere-se a um aspecto formal que determina o futuro entendido como um chegar a si, ou seja, a própria formação de identidade existencial. Este aspecto, por sua vez, não é uma propriedade do futuro, mas a forma como ele acontece.A expressão como ele esta determinado, parece-me, aponta para este aspecto de modalização e não de essencialização.

[2] O caráter da temporalização especifica a dimensão modal da determinação do futuro (que não está associada com o tradicional problema das modalidades do tempo, por exemplo, a necessidade do passado e 
contingência do futuro). Neste sentido, a finitude responde à pergunta sobre como temporaliza-se o chegar a si próprio.

[3] Não obstante, o ekstase do futuro tem um horizonte, isto é, é um deslocamento em direção a ... Em se tratando de um chegar a si mesmo, a um si mesmo próprio, o horizonte de direcionamento é a existência própria, singular. No caso do vir a si mesmo autêntico, a identidade formada será de um existente que individua-se como a possibilidade insuperável da negatividade. Ou seja, é uma identidade que não esquece a possibilidade existencial e sua finitude ou negatividade. O problema é como o futuro originário e autêntico representa um chegar a si de uma existência insuperavelmente finita.

[4] O deslocamento a si que é o futuro acontece de um tal modo que ele encerra, ele totaliza as possibilidades. Ou seja, aquelas possibilidades em que cada um já está lançado são individualizadas como próprias, sendo reunidas em um todo singular (não necessariamente consistente). Deste modo o chegar a si individualizador proporciona uma compreensão existenciária. Note-se que não é uma compreensão existencial, o que indica a concretude e singularidade da compreensão. Como compreensão, porém, não se trata de um ato intelectual ou cognitivo (apesar de poder modificar-se em tal), mas de um projetar, de um lançar-se. Neste caso, trata-se de uma projeção singular na negatividade, na falta de fundamento das próprias possibilidades. Neste sentido, a finitude do chegar-asi-mesmo, que é o futuro, reside no modo como ele ocorre, que proporciona uma individuação que está sendo mantida em um existir concreto nas possibilidades negativadas.

[5] Mais uma vez aparece o conceito de sentido, sendo ressaltado que o existir na negatividade é compreendido a partir da perspectiva de um chegar à própria identidade. Neste caso, há um detalhe importante que está na diferença entre existir como negatividade (presente na frase [3]) e existir na negatividade. Existir como a possibilidade da negatividade não é ainda a formação de individualidade finita, mas é a condição existencial geral de todo ser-humano. Existir na negatividade é aquilo que ocorre quando em cada um acontece a individuação. Trata-se de um existir que se projeta singularmente nas próprias possibilidades negativadas. Ora, a finitude do futuro está no modo como ele opera esta individuação, neste caso, possibilitando que cada um seja propriamente as possibilidades sem fundamento que lhe têm qualificado impessoalmente.

[6] A finitude não atinge uma suposta infinitude ou continuidade de uma possível série temporal. Com ela se pretende fixar o caráter feno- 


\section{6}

menal da temporalidade originária, isto é, o modo como ela aparece, como ela se apresenta e se mostra. Ela mostra-se como o sentido pelo qual devemos entender o que é o projetar-se em possibilidades da existência humana. Em termos estritos, $\mathrm{Y}$ ser o sentido de $\mathrm{X}$ quer dizer que $\mathrm{Y}$ está formalmente presente na projeção de $\mathrm{X}$, e que ao tornar-se $\mathrm{Y}$ explícito e tematizado obtem-se um ganho explanatório de X. Neste caso, o futuro é explanatório do ser para a morte, ou então, o obter identidade é o que permite compreender o lançar-se em possibilidades negativadas.Assim sendo, a finitude do futuro (e da temporalidade) nos mostra que o modo como o ser humano chega a ter uma individuação é quando acontece de existir projetando-se em possibilidades negativas.

Que o futuro originário seja finito significa, portanto, que a individuação acontece numa existência que está em suas possibilidades reconhecendo sua insuperável negatividade. Seria pensável uma ontologia do ser-humano na qual a individuação fosse gerada pela posse de propriedades, quando cada indivíduo surgisse como a instanciação de propriedades, mas esta não seria aquela resultante da ontologia fundamental. Segundo Heidegger, ganhar identidade é reconhecer-se como mera possibilidade sem fundamento, ou então, quando a identidade própria, que parecia estável como um feixe de propriedades, perde vigência enquanto tal, mostrando-se como identidade impessoal. Curiosamente, o futuro mostra-se como finito, pois a identidade própria que pode chegar é uma possibilidade negativa, sem fundamento, sem estabilidade. Em resumo, a finitude da temporalidade originária é um traço do seu auto-produzir-se, de sua temporalização. Mais precisamente, é uma característica de seu aparecer, de sua manifestação fenomenal, que diz respeito ao chegar a si mesmo ou formar uma identidade em termos de uma possibilidade negativada, limitada. Ao possibilitar uma individuação negativada, o futuro originário (chegar a si) é finito ${ }^{19}$.

Uma apresentação da finitude da temporalidade originária ainda demandaria o exame da finitude dos ekstases do passado e do presente, consequentemente, um exame da finitude associada com a herança não escolhida de possibilidades, bem como da estabilização impessoal que elas recebem no presente. Em termos gerais, porém, a temporalidade originária refere-se ao modo mais elementar de autoprodução da temporalidade, caracterizada por ekstases e esquemas horizontais, que perfazem uma unidade não serial.A temporalização a partir do futuro é qualificada como finita, e é a partir das possíveis configurações triádicas dos ekstases que o cuidado pode ser interpretado. 


\section{As modificações da temporalidade originária}

É indiscutível, repetindo, que este conceito de tempo pouco mostra das características mais usuais nas noções filosóficas de tempo. Determinação teleológica e não serial do futuro, finitude, e ausência de serialidade parecem conduzir a uma noção absolutamente dissociada dos significados daquelas expressões que são usadas para manifestar o tempo e a temporalidade. Não obstante, o argumento que justifica a preservação da denominação de tempo para este modelo interpretativo baseia-se no reconhecimento da gênese dos diferentes modos do tempo a partir da temporalidade originária. Além disso, é a função explanatória que a temporalidade originária desempenha em relação aos outros modos do tempo que determina a relação de dependência entre eles.

O modo do tempo com o qual o ser-humano lida cotidianamente não é a temporalidade originária.A temporalidade originária sofre modificações em suas estruturas, gerando um modo diferenciado do tempo, que Heidegger chama de tempo do mundo (Weltzeit).Trata-se do tempo tal como é experimentado ou como aparece nas ocupações cotidianas, e que pode, ele mesmo, ser objeto de comportamentos operativos e ocupacionais. Esta modo do tempo aparece exatamente nos comportamentos medianos em que cada existente humano está inserido, no qual, portanto, é possível uma primeira forma de intratemporalidade. Este modo do tempo pode ser descrito como um certo "fluxo" temporal experimentado cotidianamente pelo Dasein $^{20}$. Neste caso, o tempo do mundo apresenta uma característica serial, sendo experimentado como uma seqüência de momentos qualitativos que são encontrados na cotidianidade da vida humana. A serialidade aparece na estrutura deste modo temporal, diferentemente da temporalidade originária. Não obstante, os elementos desta série não são instantes pontuais não qualitativos, mas o que Heidegger denomina - certamente com uma linguagem característica - de "agoras". Os componentes desta série formam uma seqüência de "agoras", que estão em relações seqüenciais. Entretanto, estes componentes são qualitativos. O tempo do mundo, além da serialidade também é caracterizado pela databilidade, extensão, significância e publicidade.

A databilidade dos momentos do tempo experimentado cotidianamente refere-se ao fator relacional dos seus componentes, ou seja, o "agoras" são relativos a eventos que os qualificam, que os marcam com uma data. A experiência cotidiana do tempo ainda não encontra um tempo quantitativo, mas sim momentos datados por relação a eventos. 


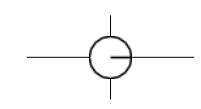

\section{8}

Estes momentos não são pontuais, mas os assim ditos "agoras" têm uma extensão. Eles são estendidos em um período, que é limitado pelo antes e pelo depois.Tais componentes ainda são caracterizados pela significância, isto é, pela relação teleológica a algum propósito. Os momentos do tempo do mundo são apropriados ou inapropriados para algo, e não momentos desprovidos de conteúdo, que deveriam ser subseqüentemente interpretados. Do mesmo modo que em relação à fenomenologia da ação teleológica cotidiana, o comportamento em relação ao tempo já os encontra em significações, isto é, temos uma seqüência de agoras tomados como adequados ou não para certos fins ou propósitos. Por fim, estes momentos datados, estendidos e significativos são públicos. Esta característica tem por base a socialidade constitutiva da existência humana, que estabiliza impessoalmente normas para ações e práticas cotidianas. Neste sentido, os componentes do tempo do mundo podem ser compreendidos e experimentados por outras pessoas de acordo com a sua concreta significatividade, extensão e datação.

O terceiro modo do tempo é chamado por Heidegger de tempo em sentido vulgar ou comum, e é aquele que tem merecido maior atenção na história da filosofia e da ciência. Ele tem origem pelo nivelamento da databilidade e significatividade do tempo da cotidianidade, resultando em uma série de instantes idênticos e não relacionais, como um meio homogêneo capaz de ser visto como infinito. Este tempo dissociado dos propósitos em que a existência humana se engaja pode aparecer como totalmente independente da esfera da vida humana e de suas ocupações. Este é o tempo que pode ser contado e medido, além de servir como meio para a medição. Neste sentido, o nivelamento nas estruturas do tempo do mundo acompanha a modificação na compreensão de ser que possibilita o encontro com objetos dissociados de qualquer propósito ou vínculo com a existência humana. A diferença nos componentes desta série está dada pelas relações de anterioridade e posteridade que se estabelecem entre tais componentes. É possível descrevê-los, então, como presentes, como já passados ou como ainda por vir.

O central na cronologia fenomenológica de Heidegger não está apenas na apresentação destes três modos do tempo, mas em pretender que exista uma relação de dependência hierárquica entre eles. Esta dependência é formulada em termos de origem, operada por nivelamentos motivados nas estruturas dos modos mais básicos, gerando um modo complexo como é o tempo desengajado. A dependência é mediada, no sentido de que o tempo comum origina-se de um modo já modificado, 
o tempo do mundo. Não há uma dependência direta em relação à temporalidade originária. Por sua vez, o tempo mundano tem sua origem na temporalidade originária, precisamente por modificações na estruturas do eksates, mas sobretudo pela formação de serialidade. Esta é diferença fundamental: a ausência de serialidade na temporalidade originária, e a sua presença qualitativa e quantitativa nos outro modos.

O componente genealógico da integração dos três modos do tempo é o aspecto decisivo na formulação do modelo hermenêutico da temporalidade. Descrever a dependência estrutural dos modos do tempo é condição para o sucesso na finalização da analítica da existência e da interpretação do ser a partir do tempo. De outro lado, é o componente genealógico que oferece a resposta para a primeira objeção que desperta a doutrina heideggeriana do tempo: por que denominar de tempo (ou de modo do tempo) um fenômeno não serial, composto por elementos que não estão em relações seriais? A denominação é justificada, pretende Heidegger, porque o tempo do mundo cotidiano depende explicativamente da temporalidade originária, e porque o tempo desengajado é dependente do tempo do mundo.A justificativa para chamar de tempo a multiplicidade não serial de ekstases horizontais finitos reside em seu papel de origem dos modos do tempo. Diz Heidegger:"Por conseguinte, caso se demonstrasse que o 'tempo' acessível para a compreensão comum do Dasein não é originário, mas sim que deriva da temporalidade própria, ficaria justificado que, conforme ao princípio a potiori fit denominatio, chamemos tempo originário a temporalidade agora descoberta" (HEIDEGGER, 1986, p.329).

A justificativa desta posição, no entanto, apresenta dificuldades evidentes, caso a dependência seja entendida de modo simples. Blattner, (1999), apresentou uma reconstrução detalhada da relação de dependência originadora, na qual esta dependência é formulada em termos recíprocos, sendo de natureza explanatória. Inicialmente, haveria uma dependência recíproca entre temporalidade originária e tempo mundano, mas a primeira seria o núcleo explicativo da segunda. Neste nível ainda se teria um duplo condicionamento na dependência: de um lado se mostraria que o ser-humano somente pode experimentar - compreender - o tempo mundano em razão da temporalidade originária; de outro, o tempo do mundo (e não a experiência cotidiana com ele) seria dependente da temporalidade originária.

No tocante ao tempo em sentido comum, a descrição de seus componentes estruturais precisa mostrar a maneira como cada um deles deriva 


\section{0}

da temporalidade originária. Neste sentido, a unificação destas formas modificadas, pois devem existir como uma unidade, é que carrega o fulcro da dependência em relação à temporalidade originária. A unidade dos momentos do tempo comum é o que lhe confere identidade própria, e como tal unidade é dependente da temporalidade originária então se pode mostrar como esta última explica o tempo em sentido usual. Que a temporalidade originária possa sofrer uma tal modificação, gerando um modo complexo como é o tempo em sentido comum, é a razão para chamar de tempo o complexo ekstático-horizontal não seqüencial que dá sentido ao ser do ser-humano (BLATT NER, 1999, p. 95 e cap. 4).

Estas observações apenas esboçam a direção geral da estrutura argumentativa de uma abordagem genealógica na cronologia fenomenológica.A despeito do seu aspecto pouco intuitivo e das demandas semânticas que traz consigo, tal modelo de tratamento do tempo possui antecedentes na tradição filosófica. De um lado, há claramente a ligação com a filosofia transcendental de Kant, num sentido radicalizado e transformado, certamente. De outro, tem sido sugerido que o procedimento de elucidar o tempo por recurso a um plano ou estrutura que não é temporal (que não possui características do explanandum) teria antecedentes em Leibniz e Plotino ${ }^{21}$. A perspectiva global de uma tese da origem do tempo a partir da temporalidade originária finita da existência humana afasta-se de tal tradição em razão do compromisso com a preservação da finitude e da erradicação de restos de teologia no pensamento do tempo 22 .

\section{Problemas e perspectivas}

Como encerramento desta contribuição quero destacar quatros temas para uma continuidade da reconstrução da cronologia fenomenológica de Heidegger. Inicialmente, a importância explicativa da historicidade no desenvolvimento do modelo da temporalidade originária.A historicidade do Dasein não é a constatação que o ser-humano pertence a algo assim como uma história universal. A historicidade é o fenômeno no qual se apresenta a estrutura de temporalização da temporalidade originária. Da mesma maneira como o primado do futuro desvela a finitude da temporalidade, a estrutura de temporalização da temporalidade desvela-se como historicidade (HEIDEGGER, 1986, p. 332). Uma justificativa para a formulação de um modo do tempo tão extraordinário seria dada pelas exigências ontológicas de uma conceitualização adequada da historici- 
dade da existência, bem como de toda possível compreensão histórica ${ }^{23}$. Este é o ponto de conexão com a historicidade e temporalidade próprias de ser, independentemente do ser-humano. O ponto é decisivo para sustentar a tese hermenêutica de que o tema principal do pensamento de Heidegger seria a pergunta pelo Dasein na história e por uma história do próprio ser (TRAWNY, 2003, p. 68).

Em segundo lugar, o modelo derivativo de tratamento da temporalidade, pelo qual se buscaria a redução de tipos de séries temporais, representaria uma diferenciação no vocabulário temporal. Já que este projeto requer a descrição de modos diferenciados do tempo, isto supõe a identificação e elucidação de um vocabulário temporal dimensionado, e não apenas linear (SANDBOTHE, 2003, p. 90-91). Assim, a adoção de uma perspectiva não reducionista, na qual não estaria mais em questão a derivação de uma série a outra, ou exame da origem de um modo do tempo a partir de uma temporalidade originária, representaria exatamente a atitude coerente com a "preservação da força elementar das palavras".

Em terceiro lugar, destaco duas objeções dirigidas para a concepção genealógica do tempo. Para Tugendhat há um erro fundamental na abordagem do tempo feita por Heidegger, que compromete todo o projeto da ontologia fundamental. A pretensão de derivar o tempo linear do tempo originário fracassaria, pois o sentido adequado do futuro, que Tugendhat interpreta como a relação para com a possibilidade da morte, entendido como o momento em que é possível não haver mais a vida individual, suporia já o tempo linear. Heidegger não teria percebido esta conexão elementar, tendo erguido um projeto fascinante que terminaria em um final melancólico pelo simples exame da dependência do tempo originário em relação ao tempo linear (TUGENDHAT, 2001a e 2001c, p. 198). Não posso discutir a objeção agora, mas observo que ela é acompanhada não apenas do exame desta relação de dependência, mas também de objeções globais aos fundamentos do projeto heideggeriano.Tugendhat não reconhece no próprio conceito de ser empregado por Heidegger uma significação que justificasse o problema do ser; ele não admite outras noções de tempo que não aquelas expressas pelas série A e B, de McTaggart. A reconstrução feita por Tugendhat do ekstase do futuro também exibe uma discordância em relação ao conceito de possibilidade existencial e de toda a ontologia da existência, pois ele não faz intervir no significado do ekstase do futuro a projeção em possibilidades.Além disso, daqui também se revela a insatisfação de Tugendhat (2001c) com a análise do mundo circundante e da ontologia da Zuhandenheit. Enfim, trata-se de uma 


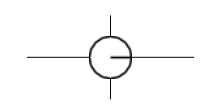

\section{2}

objeção muito contundente e que deve ser respondida com uma análise de detalhe de todos os conceitos envolvidos, em particular o conceito de futuro na sua relação com a projeção teleológica em possibilidades existenciais (de uma teleologia não seqüencial, como foi indicado acima).

Numa direção similar, mas após um exaustivo exame dos conceitos e da estrutura argumentativa presente na cronologia fenomenológica de Heidegger, Blattner (1999) sustenta que há um fracasso na derivação do tempo do mundo a partir da temporalidade originária. Mesmo reconhecendo uma dependência complexa (o que diferencia sua análise da crítica de Tugendhat), ele afirma que Heidegger não consegue ser bem sucedido no exame da origem dos modos do tempo a partir da temporalidade originária. Isto acarretaria o fracasso do idealismo temporal, e, portanto, do inteiro programa da ontologia fundamental. Estas duas avaliações críticas devem ser consideradas e avaliadas em sua correção, o que não será feito aqui. Observo apenas que o ponto central em questão é relevante para o conhecido problema da falta de publicação de todo o livro Ser e Tempo.

Por fim, quero ressaltar um aspecto sistemático no tocante ao problema da relação entre ser e nada, que passa a tomar conta das preocupações ontológicas de Heidegger ao final dos anos 20.Trata-se de uma mudança de ênfase na caracterização da relação entre ser e nada, que não é mais pensada exclusivamente a partir da negatividade da existência humana, mas sim a partir do ser em si mesmo. O fundamento explicativo desta copertinencia entre ser e nada estaria no próprio tempo, que seria caracterizado por uma negatividade estrutural. O problema da finitude de ser poderia ser visto como radicado na finitude da temporalidade, mas talvez não explicativamente dependente da finitude da existência. Cito uma longa passagem que põe o problema com clareza:

Desta forma, se anuncia um problema fundamental e difícil: em que medida na estrutura deste ser, ou seja, inicialmente na disponibilidade, não se constitui exatamente um momento negativo, na medida em que denominemos formalmente o ausencial como uma negação do presencial. Perguntado de maneira fundamental: em que medida encontra-se na temporariedade (Temporalität) em geral e também na temporalidade (Zeitlichkeit) um negativo, um não? Ou então: em que medida o próprio tempo é a condição de possibilidade da negatividade em geral? Pelo fato de que a modificação da presença em ausência, da presentidade em absentidade, que é pertencente à temporalidade (tanto ao ekstase do presente quanto aos outros ekstases), tem o caráter de 
uma negatividade, de não, o não-presente, surge a pergunta sobre onde estão as raízes deste não em geral. Uma consideração mais detida mostra que, do mesmo modo, também o não e a essência do não, a negatividade, somente podem ser interpretados a partir da essência do tempo, e que somente a partir disso deve ser esclarecida a possibilidade da modificação da presentidade para a absentidade, por exemplo. Ao fim, Hegel estava na pista de uma verdade fundamental, quando disse que ser e nada são idênticos, quer dizer, se pertencem mutuamente. A pergunta mais radical é certamente: o que torna possível uma tal copertinencia originária?" (HEIDEGGER, 1976a, p. 443)

Esta passagem também permite concluir este trabalho, retomando a citação em epígrafe.A temporalidade originária e a temporalidade de ser, precisamente pela sua finitude intrínseca (que poderia ser traduzida numa historicidade marcada pela ruptura e a descontinuidade nas tradições conceituais), estariam na origem de uma exigência de preservação conceitual e da terminologia filosófica. Tal exigência seria mais contundente quando o próprio tempo estivesse em questão, ou seja, quando estaria em andamento uma cronologia filosófica.

\footnotetext{
1 Para a sua realização, este trabalho recebeu o apoio da CAPES, no programa PROCAD/ PUC RJ-UFSM.

2 Este tem sido um tópico privilegiado na literatura secundária gerada a partir da publicação da Gesamtausgabe (ver Streeter e Oudemans, entre tantos outros).

3 Em Heidegger (1976b, p. 410), os enunciados sobre o tempo são apresentados como sendo de natureza indicativo-formal.
}

${ }^{4}$ Segundo Petkovsek (1998) esta é a única menção de Heidegger a tal expressão. Em Heidegger (1986), o termo cronologia está restrito aos estudos em ciências naturais e nas disciplinas históricas auxiliares, relativos à contagem do tempo na história, à elaboração de calendários e à datação. A passagem contém um qualificativo importante, ao afirmar que inicialmente a cronologia fenomenológica não tem a ver com medição e teoria da contagem do tempo. $\mathrm{O}$ que está presente aqui é um modo de conceber a relação entre ciência e filosofia. O ponto de insistência não é uma dissociação entre ciência e filosofia, mas sim que qualquer abordagem da estrutura temporal dos fenômenos transita para uma investigação propriamente filosófica ao transitar para uma determinação conceitual e ontológica do próprio tempo.

5 De outro lado, Heidegger insiste que Kant teria sido o único filósofo a entrar, de modo tateante não obstante, no domínio da cronologia filosófica (HEIDEGGER, 1976b, p. 200-201).

6 O conceito de totalidade concreta é originado da teoria mereológica de Husserl (ØVERENGT, 1996). 


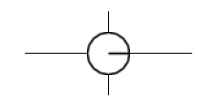

\section{4}

7 Blattner (1999, n. 54, p. 29), ressaltou esta conexão entre a tempo e diferença ontológica.

8 Neste tópico, o livro de William Blattner (1999, p. 122-126) é exemplar em clareza analítica e poder elucidatório da doutrina heideggeriana da temporalidade, e a ele farei referência direta nos pontos centrais desta contribuição.

${ }^{9}$ As dificuldades com o conceito de modo e possibilidade são notórias em Ser e Tempo. Uma introdução a análise da noção de modo (e modificação) pode ser encontrada em Hartmann (1974), e em Blattner (1999) há uma excelente análise e elucidação da noção de possibilidade existencial, que é central na problemática da temporalidade originária.

${ }^{10}$ Em 1978b (p. 255), Heidegger afirma que a temporalidade originária não é relativa à sensibilidade, sendo mais fundamental que sensibilidade, espírito e razão. Este é o ponto em que seria necessário o exame da apropriação destrutiva das abordagens do tempo feitas por Kant, por Hegel e por Husserl.

11 O tópico é mais complexo, pois a temporalidade, ao ser mostrada como o sentido do ser em geral, condicionando a compreensão de ser também condiciona todo comportamento intencional.

12 Mesmo não sendo um ponto fundamental na presente abordagem, é relevante ressaltar que importantes aproximações da fenomenologia de Heidegger com o debate anglo-americano contemporâneo já recebem importantes qualificações. Assim, a aproximação do conceito de cuidado de um certo externalismo ou perspectiva da terceira pessoa tem sido questionada em termos de uma adequada reconstrução da contribuição de Heidegger (KOLB, 1995, p. 57).

13 Tal como o faz Klaus Düsing (1980), cujo trabalho sobre a recepção moderna da doutrina kantiana da temporalidade oferece importantes análises para o empreendimento históricodestrutivo de Heidegger.

14 A formulação do ekstase do futuro a partir de considerações lingüísticas sobre o significado das partículas $Z u$ e kunft proporcionaram objeções críticas no tocante a artificialidade do jogo lingüístico desdobrado por Heidegger (ver TUGENDHAT, 2001a, p. 20, HEINZ, 2001, p. 186). Não obstante, o sentido próprio de um futuro não posterior em uma série temporal, entendido como um chegar a si mesmo a partir da projeção em possibilidades, pode ser proposto com independência de uma suposta prova filológica (é o que está presente na cuidadosa análise de Blattner 1999, e nas breves considerações de Heinz 2001, e King 2001 p. 218 225 , entre outros). O conceito chave na definição do significado do ekstase do futuro é o de possibilidade existencial e projeção em um tal tipo de possibilidades, que demanda uma análise da ação teleológica não necessariamente vinculada à busca de objetivos, e, portanto, compatível com uma teleologia não seqüencial (BLATT NER,1999, p. 107-111).

15 Este é um ponto de debate na literatura secundária, pois há passagens em que Heidegger sugere que a temporalidade originária seria a forma autêntica da temporalidade, e que os seus outros dois modos seriam formas da inautenticidade. Não obstante, a análise de Blattner (1999, p. 98-102) possui um base de análise conceitual mais sólida, estabelecendo a indiferença modal da temporalidade originária.

16 1986, p. 329. Neste ponto retorna o problema da autenticidade ou indiferença modal da temporalidade originária. Observe-se que o primado do futuro é alterável em função da temporalização da temporalidade originária no modo inautêntico, o que não revoga, porém, a primazia do futuro em relação à temporalidade originária na modalidade indiferente.

17 Como é já bem conhecido, esta limitação especifica-se em três direções conexas: a) na impossibilidade de decidir a herança de possibilidades recebidas (a partir das quais acontece a 
projeção, e que estabelece o ser para o nascimento, o outro fim para o Dasein, segundo Heidegger); b) na impossibilidade de não estar junto a entes e objetos (e que também é limitada ainda mais pelo compromisso que se instaura na direção tripartite de relacionamento com entes, para com outras pessoas, objetos, utensílios e para consigo mesmo); e c) na impossibilidade de fazer das possibilidades projetadas algo assim como uma propriedade possuída estavelmente (a possibilidade da impossibilidade, instanciada exemplarmente pela morte).

18 A longa citação que será comentada é ponto de partida para uma elucidação mais exaustiva da finitude do futuro e da temporalidade originária, a ser feita em outra ocasião. Inseri números entre colchetes para discriminar os pontos de análise.

${ }^{19}$ Em Ser e Tempo a finitude da temporalidade é relativa ao elemento negativado ou de não ser que está na existência humana. Identidade pessoal sendo constituída pela projeção em possibilidades em meio à perda da vigência de toda individuação impessoal e inautêntica. Neste caso, a relação entre ser e nada é pensada no interior da ontologia existencial. Em $O$ que é Metafisica?, a relação entre ser e nada é posta no plano de toda projeção de ser, o que implica uma finitude de ser e não apenas da existência humana. Esta mesma transposição tem que valer para a finitude do tempo, que não será mais pensada exclusivamente pela finitude da existência.

20 Tal como o fez Blattner (1999, p. 127).A partir deste momento seguirei de modo imanente as análises e reconstruções da estrutura argumentativa da cronologia fenomenológica de Heidegger, que me parecem ser as mais refinadas presentes na literatura.

21 A tese histórica foi apresentada no capítulo 5 do livro de Blattner, e certamente exige um desenvolvimento e documentação que ultrapassam o plano desta contribuição.

22 Nesta mesma direção, também há uma sugestão apontada por Hans Jonas, ao comparar a tradição gnóstica com a analítica da existência de Heidegger, sobretudo no tocante ao problema de um deflacionamento crítico do ekstase do presente. Sobre a relação entre eternidade e o modelo global de uma temporalidade modificável a partir do tempo existencial Heidegger deixa em aberto o problema de se a via negationis et eminentiae poderia oferecer um alternativa viável (HEIDEGGER, 1986, p. 427, n. 1).

23 A gênese ontológica da ciência da história, como dirigida não para fatos ou acontecimentos, mas para possibilidades, mostraria a primazia de um modo ekstático, finito e não serial do tempo.

\section{Referências Bibliográficas: \\ BLATT NER, W.Heidegger's Temporal Idealism. New York: Cambridge University Press, 1999.}

BRANDOM, R. "Heideggers Categories in Being and Time". In: DREYFUS \& HALL, H. Heidegger: A Critical Reader. Oxford: Blackwell, p. 45-64, 1992.

CROWELL, S. G. "Emil Lask: Lask, Heidegger, and the Homelessness of Logic". In: CROWELL, Steven Galt. Husserl, Heidegger, and the Space 


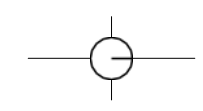

126

of Meaning. New York: SUNY Press, p. 76-92, 2001.

DÜSING, K. Objektive und subjektive Zeit. Untersuchungen zu Kants

Zeittheorie und zu ihrer modernen kritischen Rezeption. Kant-Studien, v. 71

(1), p. 1-34, 1980.

HARTMANN, K. "The logic of deficient and eminent modes in Heidegger". In: Journal of the British Society for Phenomenology. 5(2): 118134, 1974.

HEIDEGGER, M. Sein und Zeit. 17. Tübingen: Max Niemeyer Verlag, 1986.

. Was ist Metaphysik? (Neunte Auflage) Frankfurt am

Main:Vittorio Klostermann, 1965.

. O conceito de tempo, Traduçao de Marco Aurélio Werle,

Cadernos de Tradução, n. 2, DF/USP, p. 6-39, 1997.

. Die Grundprobleme der Phänomenologie. 2. ed. In:

Gesamtausgabe 24 (Sommersemester 1927). Frankfurt am Main:

Vittorio Klostermann, 1976a.

. Frühe Schriften. In: Gesamtausgabe 1. Frankfurt am Main:

Vittorio Klostermann, 1978a.

. Logik. Die Frage nach der Wahrheit. In: Gesamtausgabe 21

(Wintersemester 1925/ 26 ). Frankfurt am Main:Vittorio Klostermann, 1976b.

. Metaphysische Anfangsgründe der Logik. In: Gesamtausgabe 26 (Sommersemester 1928). Frankfurt am Main:Vittorio Klostermann, $1978 b$.

HEINZ, M. "Das eigentliche Ganzseinkönnen des Daseins und die Zeitlichkeit als der ontologische Sinn der Sorge (§ 61-66)". In:

RENTSCH, Thomas. Klassiker Auslegen: Martin Heidegger/Sein und Zeit. Berlin: Akademie Verlag, p. 169-197, 2001.

JONAS, H. “Gnosis, Existentialismus und Nihilismus”. In: Gnosis und spätantiker Geist (Zweiter Teil). Göttingen:Vandenhoeck \& Ruprecht, p. 359-379, 1993.

KING, M. A. Guide to Heidegger's Being and Time. Albany: SUNY, 2001. 
KOLB, D. "Raising Atlantis: the Later Heidegger and Contemporary Philosophy". In: BABICH, B. (Ed.). From Phenomenology to Thought, Errancy, and Desire. Dordrecht: Kluwer Academic Publishers, p. 55-69, 1995.

McTAGGART, J. M. E. "The Unreality of Time”. In: POIDEVIN, R. L. \& MACBEATH, M. The Philosophy of Time. Oxford: Oxford University Press, p. 23-34, 1993.

OUDEMANS, T. C. W. "Heideggers 'logische Untersuchungen'”. In: Heideggers Studies 6: 85-105, 1990.

ØVERENGET, E. "The Presence of Husserl's Theory of Wholes and Parts in heidegger's Phenomenology". In: Research in Phenomenology 26: 171-197, 1996.

PETKOVSEK, R. Heidegger-Index (1919-1927). Ljubljana, 1998.

RENTSCH, T. “Zeitlichkeit und Alltäglichkeit (§ 67-71)”. In:

RENTSCH, Thomas. Klassiker Auslegen: Martin Heidegger/Sein und Zeit. Berlin: Akademie Verlag, p.200-228, 2001.

SANDBOTHE, M. "Von der Grundverfassung des Daseins zur Vielfalt der Zeit-Sprachspiele”. In: Thomä, D. Heidegger Habdbuch. Stuttgart:

Verlab J. B. Metzler, p. 87-92, 2003.

STREETER, R. 'Heidegger's formal indication: a question of method in Being and Time". In: Man and World 30: 413-430, 1997.

TRAWNY, P.Martin Heidegger. Frankfurt/ New York: CampusVerlag, 2003.

TUGENDHAT, E. "Heidegger und Bergson über die Zeit". In: Aufsätze 1992-2000. Frankfurt am Main: Suhrkamp, p. 11-26, 2001a. . "Schwierigkeiten in Heideggers Umweltanalyse". In: Aufsätze 1992-2000. Frankfurt am Main: Suhrkamp, p. 109-137, $2001 b$. . "Zeit und Sein in Heideggers Sein und Zeit". In: Aufsätze 1992-2000. Frankfurt am Main: Suhrkamp, p. 185-198, 2001c. 